\title{
The impact of soil initialization on regional decadal climate predictions in Europe
}

\author{
Marcus Breil ${ }^{* * *}$, Natalie Laube ${ }^{* *}$, Joaquim G. Pinto, Gerd Schädler \\ Institute of Meteorology and Climate Research, Karlsruhe Institute of Technology, 76344 Eggenstein-Leopoldshafen, Germany
}

\begin{abstract}
Inaccuracies in soil initialization, caused by unbalanced soil conditions, are one possible reason for biases in regional climate predictions. Therefore, in the present study, stand-alone simulations with a land surface model are performed in order to create balanced soil conditions. The impact of different atmospheric forcing data on the quality of the stand-alone simulation is evaluated by comparing the results to observations. The results reveal that stand-alone simulations driven by the atmospheric reanalysis ERA-Interim give the best results in terms of the correlation to observed soil temperatures and soil water contents. Based on these results, a regional climate simulation is initialized with these balanced soil conditions and compared to a reference run with unbalanced soil. The results show that the soil initialization of decadal climate simulations generally affects the spatial variability of summer precipitation in Europe. However, no systematic added value of the initialization with balanced soil conditions is evident for precipitation. Still, a clear added value can be observed for the simulated summer temperatures, especially in warm and semi-arid regions like the Iberian Peninsula. Since the balanced soil initialization contains less soil water than the unbalanced one, this simulation is able to reproduce the characteristic drought stress in summer in a more realistic way. We conclude that proper soil initialization can lead to potentially better decadal predictions, particularly for warm and semi-arid regions. An accurate soil initialization may therefore become essential, especially in European areas that are expected to become warmer and drier in summer due to climate change, e.g. Central and Eastern Europe.
\end{abstract}

KEY WORDS: Soil initialization - Regional climate predictions · Land surface model . COSMO-CLM

\section{INTRODUCTION}

Global and regional seasonal to decadal climate predictions have become an active field of research during the last few years (Mieruch et al. 2014, Marotzke et al. 2016). The behavior of the climate system on these timescales is a result of the interaction of the fast (i.e. the atmosphere) and the slow (mainly the oceans, cryosphere and soil) components of the system and thus presents a combined initial and boundary value problem. Whereas oceans and the cryosphere are the most important slow system components on the global scale, the focus of the present paper will be on soils, since regional predictions

*Corresponding author: marcus.breil@kit.edu

${ }^{* *}$ These authors contributed equally to this work are done mainly for land surfaces. In this context, soil conditions can affect the regional energy balance in a number of ways (summarized e.g. in Seneviratne et al. 2010). Changes in the soil water content, for instance, affect soil temperature by changing the soil heat capacity and the evapotranspiration rate. Changes in soil temperature, in turn, affect the amount of turbulent heat exchange and thus regional climate conditions. The corresponding processes between soil, vegetation and atmosphere are modeled in land surface models (LSMs).

During the last few years, considerable progress in the development of LSMs has been made. Whereas in the early years of climate modeling, soil and land sur-

() The authors 2019. Open Access under Creative Commons by Attribution Licence. Use, distribution and reproduction are unrestricted. Authors and original publication must be credited. 
faces were treated in a rather crude way (e.g. Shukla \& Mintz 1982), sophisticated and more realistic LSMs are now being integrated in Earth system models (ESMs). Some well-known examples of the current LSM generation are the Community Land Model (Oleson et al. 2013), NOAH (Niu et al. 2011) and JSBACH (Roeckner et al. 2003). The importance of and interest in these models is also reflected in various model intercomparison projects, like the African Monsoon Multidisciplinary Analysis (AMMA) Land Surface Model Intercomparison Project (ALMIP, Boone et al. 2009), the Global Land Atmosphere System Study (GLASS, van den Hurk et al. 2011), the Snow Models Intercomparison Project (SnowMIP, Etchevers et al. 2004) and the upcoming Land Surface, Snow and Soil Moisture Model Intercomparison Project (LS3MIP, van den Hurk et al. 2016), to name just a few.

In all cases, however, besides a proper modeling of the processes involved, a proper initialization of all soil layers is essential for successful regional climate predictions (Dirmeyer et al. 2013, Khodayar et al. 2015). The relative importance and the time required to approach equilibrium of soil and land surfaces in LSM simulations varies regionally and depends e.g. on soil type, soil moisture availability and vegetation cover (Koster \& Suarez 2001, Koster et al. 2004, Khodayar et al. 2015). In this context, a long-lasting problem for the initialization of regional climate predictions is the lack of spatially and temporally dense observations of soil temperature and soil moisture. Whereas some datasets exist for the upper soil layers, data for the deeper soil layers are limited to a very small number of observational sites, making an accurate soil initialization with observations impossible for regional climate predictions. Therefore, LSMs in regional climate simulations are generally initialized with interpolated soil conditions, obtained from general circulation models (GCMs). But since in most cases, the model physics of the implemented LSMs differ between the regional climate model (RCM) and the GCM, a consistency problem arises. A drift of the model results is the consequence until balanced soil conditions are reached. Results of recent studies indicate that (depending on season and soil type), soils may take months to years to adjust (Khodayar et al. 2013, 2015), i.e. the timescales that seasonal to decadal climate predictions are interested in. Due to the long timescales (depending on region and soil water availability), the soil conditions are not only initial values, but also act as boundary values over years. Thus, since information diffuses upward as well as downward in the soil, a wrong soil initialization causes unrealistic values for soil moisture and soil temperature and thus affects atmosphere and climate via heat and moisture fluxes (Khodayar et al. 2013).

To avoid such a model drift due to spurious soil initialization, a spin-up of several years is usually performed in advance of the simulation period, allowing the RCM soil to adjust. An overview of this and other initialization methods (e.g. the assimilation of satellite data) can be found in Kothe et al. (2016). For regional decadal predictions with their large amount of simulations (ensemble method), this approach is too time-consuming and not feasible. Another possibility to create balanced soil conditions for the initialization of RCMs is to use LSM stand-alone simulations. In this case, the LSM is not coupled to an RCM, but driven by external forcing data (e.g. reanalysis). Such simulations consume less computing time, so that long time periods can be simulated. In consequence, balanced soil conditions for a large number of simulations can be created (also for different spatial resolutions), representing the best approximation of the actual soil state for the initialization of regional climate predictions, which might improve their simulation results.

In this paper, we present the results of such standalone simulations driven by different forcings based on reanalysis datasets, and evaluate their performance by comparing the simulation results with observations, to obtain the best possible initial soil conditions. Then, the simulated soil temperature and soil moisture conditions are used to initialize coupled RCM simulations driven by ERA-Interim (Dee et al. 2011). The results of these runs with balanced soil conditions are compared to coupled runs with an unbalanced initialization (ERA-Interim soil conditions), to assess the impact of a balanced soil initialization on the simulation results under quasi-perfect lateral boundary conditions and to identify a possible added value for regional decadal predictions.

\section{MODELS AND SIMULATION SETUP}

\subsection{VEG3D}

In this study, the LSM VEG3D is applied for the stand-alone simulations as well as the coupled RCM simulations. VEG3D is a multilayer LSM developed at the Karlsruhe Institute of Technology (KIT) and assessed in various studies (Braun \& Schädler 2005, Breil \& Schädler 2017, Breil et al. 2018). In VEG3D, the heat conduction is water-dependent and parameterized after Johansen (1977). The parameterization 
of the soil water transport is based on the approach of van Genuchten (1980). Ten soil layers are used for the numerical solution of the corresponding equations which increase exponentially to the bottom at $15.0 \mathrm{~m}$ depth. The parameterization of roots is derived from Schenk \& Jackson (2003). The root zone has its maximum within $0-1.0 \mathrm{~m}$ and reaches down to $2.0 \mathrm{~m}$. The coupling between the soil surface and the atmosphere is done via a massless vegetation layer. This layer has its own canopy temperature and specific humidity derived iteratively from the canopy's energy balance. Based on these quantities, the turbulent heat fluxes are parameterized according to Monin-Obukhov similarity theory.

\subsection{COSMO-CLM}

To be able to use balanced soil conditions from VEG3D stand-alone runs in decadal climate predictions, VEG3D is coupled to the RCM COSMO-CLM (CCLM, Rockel et al. 2008). CCLM is the climate version of the 3-dimensional nonhydrostatic weather forecast model COSMO (Baldauf et al. 2011). Its physical parameterizations and dynamics are described in detail in Doms \& Baldauf (2015).

The coupling between CCLM and VEG3D (CCLMVEG3D, Breil et al. 2017) is realized via OASIS3MCT (Valcke et al. 2015). OASIS3-MCT is a combination of the OASIS3 coupler and the Model Coupling Toolkit (MCT, Larson et al. 2005). The communication between CCLM and VEG3D is accomplished via the Message Passing Interface (MPI) library. The exchange of all coupling fields between the models is arranged by the unified OASIS interface in CCLM (Will et al. 2017).

\subsection{Experimental setup}

\subsubsection{Stand-alone simulations}

To investigate the effects of, on the one hand, different atmospheric forcings and, on the other hand, the spatial resolution of the external data (land use and soil type) on the equilibrium of the soil conditions, 2-dimensional VEG3D stand-alone simulations with different forcings on different spatial resolutions are performed. In a first simulation, VEG3D runs on a spatial resolution of $0.5^{\circ}(55 \mathrm{~km})$, driven by forcing data derived from the WATCH project (Weedon et al. 2010). The simulation covers the period 1960-2010. The period 1960-1990 is driven by the WATCH WFD dataset, the second period $1990-2010$ by WATCH WFDEI. To achieve a smooth transition between the 2 datasets, a 2 yr spin-up run initialized with the soil temperature and moisture fields of the WATCH WFD run in 1990 was performed in advance of the WATCH WFDEI simulation. Since only WATCH WFDEI data are used for the evaluation, hereafter we name this simulation VEG3D-WFDEI. In a second stand-alone simulation, VEG3D runs on a spatial resolution of $0.22^{\circ}(25 \mathrm{~km})$, driven by the European Centre for Medium-Range Weather Forecasts (ECMWF) atmospheric reanalysis of the 20th century (ERA20C; Poli et al. 2013) (VEG3D-ERA20C). For this, the ERA-20C data is interpolated to the $25 \mathrm{~km}$ grid of VEG3D. The covered time period in this case is 1955-2010. For the third simulation, VEG3D runs on a spatial resolution of $0.0625^{\circ}(7 \mathrm{~km})$, driven by the ECMWF ERA-Interim reanalysis data (VEG3DERAINT), interpolated to the $7 \mathrm{~km}$ VEG3D grid, lasting from 1979 to 2010. All forcing datasets comprise the $2 \mathrm{~m}$ air temperature and $2 \mathrm{~m}$ specific humidity, precipitation (snow and rain separately), incoming short- and longwave radiation, $10 \mathrm{~m}$ wind speed and surface pressure. In advance of all 3 simulations, a spin-up run with cyclic forcing data of the starting year was repeated 7 times to reach already balanced soil conditions at the beginning of each simulation period.

In each run, the soil columns are discretized into 10 non-equidistant layers till a depth of $15.0 \mathrm{~m}$. The used time step is $300 \mathrm{~s}$. The external data are derived for the different spatial resolutions from Global Land Cover 2000 (GLC2000, Bartholomé \& Belward 2005) for the land surfaces and the Harmonized World Soil Database (HWSD, Fischer et al. 2008) for the soils.

The model domain for VEG3D-WFDEI and VEG3DERA20C is identical to that of the Coordinated Downscaling Experiment - European Domain (EUROCORDEX, Jacob et al. 2014), whereas the VEG3DERAINT domain only comprises Central Europe, as shown in Fig. 1. Thus, due to these different model domains and the different time frames used, the results of all 3 stand-alone runs are only evaluated for the overlapping Central Europe region and the time period 1990-2010 (Section 4.1). Based on these analyses, an optimal model setup for VEG3D standalone runs will be derived.

\subsubsection{Coupled simulations}

Two decadal climate simulations for Europe, using different soil conditions for the initialization, are per- 


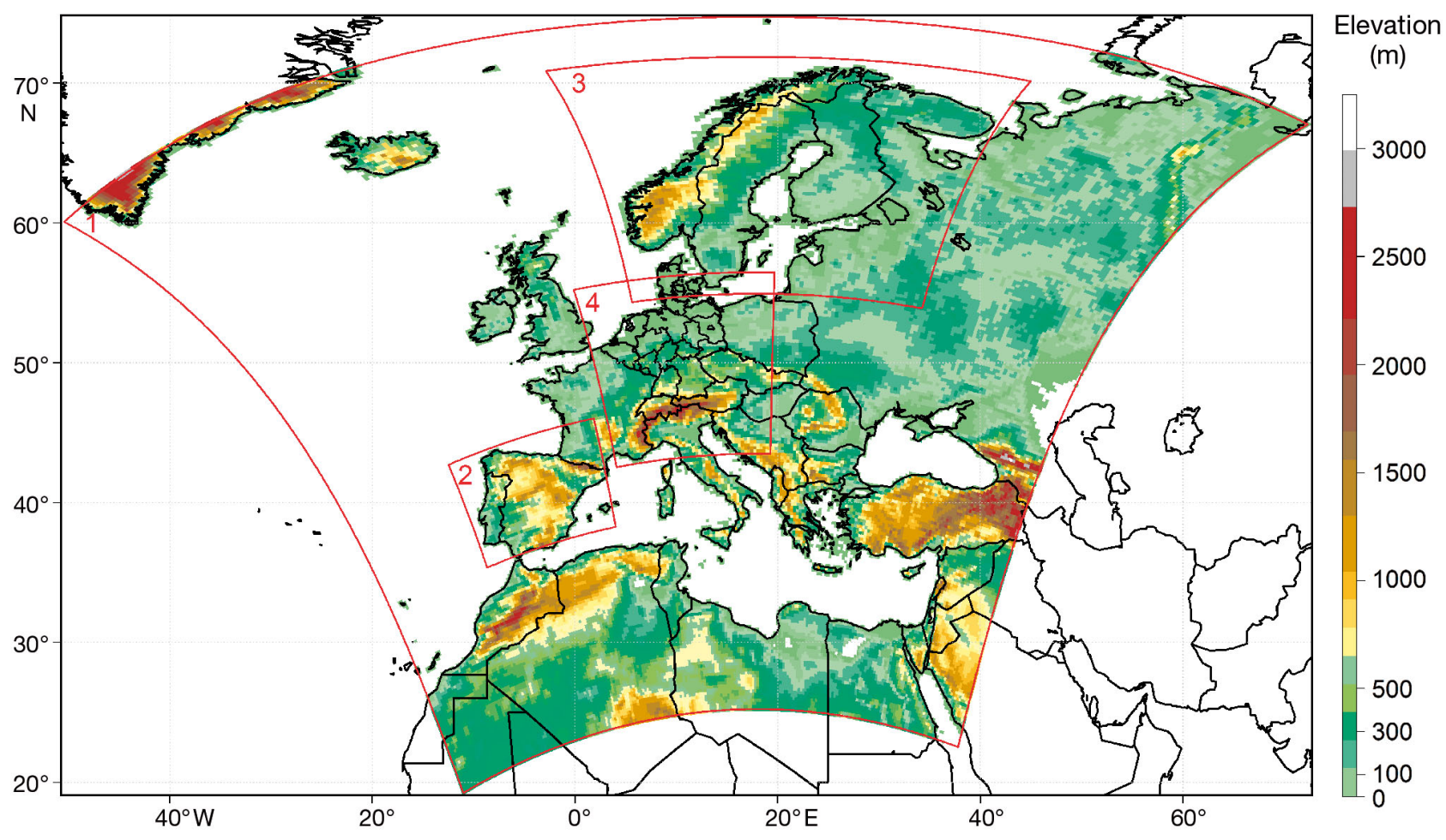

Fig. 1. Topography of the model domain (colored area) for the coupled CCLM-VEG3D simulations (1, identical to the EUROCORDEX domain; Jacob et al. 2014) and the VEG3D stand-alone simulations (4, Central Europe), including the evaluation regions Iberian Peninsula (2) and Scandinavia (3)

formed with CCLM coupled to VEG3D. Both simulations are driven by ERA-Interim at the lateral boundaries and at the lower boundary over sea, and start on January 1, 2001 and end on December 31, 2010. By using such quasi-perfect lateral boundary conditions, the pure impact of a balanced soil initialization on the simulation results can be assessed and a possible added value for regional decadal predictions can be identified. In the first run, the soil is initialized with the soil moisture and soil temperature fields of ERAInterim, which are not in balance to VEG3D. This simulation is taken as the reference run, hereinafter referred to as CCLM_VEG3D_REF. In the second run, the initial conditions of CCLM_VEG3D_REF are replaced by balanced soil moisture and soil temperature values (CCLM_VEG3D_INIT). To create these balanced soil conditions, a transient VEG3D standalone run is performed beforehand with the optimal external forcing derived from the analyses in Section 4.1. The model domains for this stand-alone simulation and the coupled runs are identical to the EUROCORDEX domain (Fig. 1). The horizontal grid spacing is $0.22^{\circ}$. In the vertical direction, the atmosphere is divided into 40 levels. The time step of CCLM and VEG3D is $150 \mathrm{~s}$, which is identical to the coupling time step of both models.

\section{VALIDATION DATA}

\subsection{Measurement sites}

The stand-alone simulation results are compared to observed soil conditions at measurement sites as well as spatial validation datasets. For the stational observations, data from the European Fluxes Data Cluster (EFDC, www.europe-fluxdata.eu) are used. The EFDC is a collection of observational data from several databases, projects and measurement sites all across Europe since 1996. For the present study, 34 stations with long and consistent time series are selected. Although the datasets are quality-controlled, missing metadata (e.g. about the measurement depths) and differing measurement periods make the validation of the stational data a challenging task. Furthermore, the land use classes and soil types at the point measurements of the stations do not necessarily have to correspond to the ones used in the 2-dimensional standalone simulations. Thus, differences between the simulated and the observed soil conditions are at some points unavoidable. The comparison of the standalone simulations results with the in situ observations is done for the soil water content, the soil temperature as well as for the latent and the sensible heat fluxes. 


\subsection{Spatial datasets}

The spatial datasets for the validation are the ERAInterim reanalysis, the European Space Agency Climate Change Initiative (ESA_CCI) soil moisture data (Dorigo et al. 2015) and a gridded soil moisture dataset from the German Weather Service (DWD). Both the ERA-Interim and the DWD soil data are simulation results of LSMs. For ERA-Interim, the LSM Tiled ECMWF Scheme for Surface Exchange over Land (TESSEL, Viterbo \& Beljaars 1995) is used, driven by an atmospheric forcing nudged to observations on a spatial resolution of $0.5^{\circ}$. In TESSEL, the soil column is discretized with 4 layers to a depth of $2.89 \mathrm{~m}$. An implemented tile approach allows different land use classes within 1 grid box (van den Hurk et al. 2000), but it includes only 1 single soil type (loamy sand), which was already critically discussed by Balsamo et al. (2009).

For the DWD data, the agrometeorological model AMBAV (Löpmeier 1983) is used to simulate the soil water content at measurement sites down to a depth of $0.6 \mathrm{~m}$. AMBAV is driven by the measured meteorological conditions at the stations and the results are interpolated to a $1 \times 1 \mathrm{~km}$ Gauss-Krüger grid for Germany. Only 1 land use class (grass) and only 1 soil type (sandy loam) are considered.

The ESA_CCI soil moisture data are satellite observations sampled with active and passive microwave sensors. Thus, moisture data can only be derived for the uppermost centimeters of the soil. The dataset is globally available in a spatial resolution of $25 \mathrm{~km}$ for the period 1978-2014. Since the soil moisture of the upper soil is the only quantity available for all 3 spatial datasets, the spatial validation in Section 4.1.2 is only done for this variable (TESSEL: 0-28 cm, AMBAV: 0-60 cm, VEG3D: 0-50 cm).

\section{RESULTS}

\subsection{Validation of VEG3D stand-alone simulations}

\subsubsection{Comparison with EFDC stations}

To consider the impact of differences in the external data (land use class, soil type) between the measurement sites and the stand-alone simulations on the validation results, the EFDC stations are classified into 4 categories: Fits (both land use class and soil type of the station agree with the ones used in the stand-alone simulation), Mixed (only one of them fits), Non-fitting (no match) or All (all 34 stations are considered). The number of stations in each category are summarized for all 3 stand-alone simulations in Table 1. The number of fitting land use classes or soil types (Fits + Mixed) is lowest for VEG3D-WFDEI (17 Fits + Mixed, $55 \mathrm{~km}$ spatial resolution of the external data) and highest for VEG3D-ERA20C (23 Fits + Mixed, $25 \mathrm{~km}$ ), but with a further increase in the spatial resolution (VEG3D-ERAINT, $7 \mathrm{~km}$ ), the number of fits does not increase anymore.

Fig. 2 shows the root mean square error (RMSE) and the correlation of the simulated monthly mean soil water content in the uppermost soil layers, soil temperatures in the uppermost soil layers, latent and sensible heat fluxes compared to the observed ones at the stations. The results are shown for each driving dataset (different colored bars) and each station category. With the classifications shown, we can distinguish between the impact of the precision of the external data (differences between each station category) and the impact of atmospheric forcing (differences between the colored bars within a category) on the quality of the simulation results.

For soil water content (Fig. 2a), VEG3D-WFDEI has the lowest RMSE over all stations, and VEG3DERAINT the highest. But concurrently, VEG3DERAINT shows the clearly highest correlation to the observations. VEG3D-ERA20C has a remarkably low correlation in contrast to the other 2 simulations. The RMSEs of the 4 different station categories are very heterogeneous. Here, the Fits clearly have the lowest values, and the Mixed have the highest. To assess the relative importance of the 2 factors 'external data' and 'atmospheric forcing', we performed a KruskalWallis test ( $\alpha=0.1$ ) by grouping the data according to the 2 factors (Table 2); the test showed that the RMSE varies significantly $(p=0.06)$ with the external data, and the correlation varies significantly $(p=0.03)$ with the atmospheric forcing. Thus, the bias of the standalone simulations is considerably affected by the precision of the external data. But, for the correlation to the EFDC data, atmospheric forcing is more important, since it mainly depends on the seasonal cycle of the atmospheric conditions.

Table 1. Number of stations in the 4 categories: Fits (both land use class and soil type of the station agree with the ones used in the stand-alone simulation), Mixed (only one of them fits), Non-fitting (no match), and All (all 34 stations are considered), for the VEG3D stand-alone simulations

\begin{tabular}{|lcccc|}
\hline Stand-alone simulation & Fits & Mixed & Non-fitting & All \\
\hline VEG3D-WFDEI & 6 & 11 & 17 & 34 \\
VEG3D-ERA20C & 6 & 17 & 11 & 34 \\
VEG3D-ERAINT & 7 & 14 & 13 & 34 \\
\hline
\end{tabular}



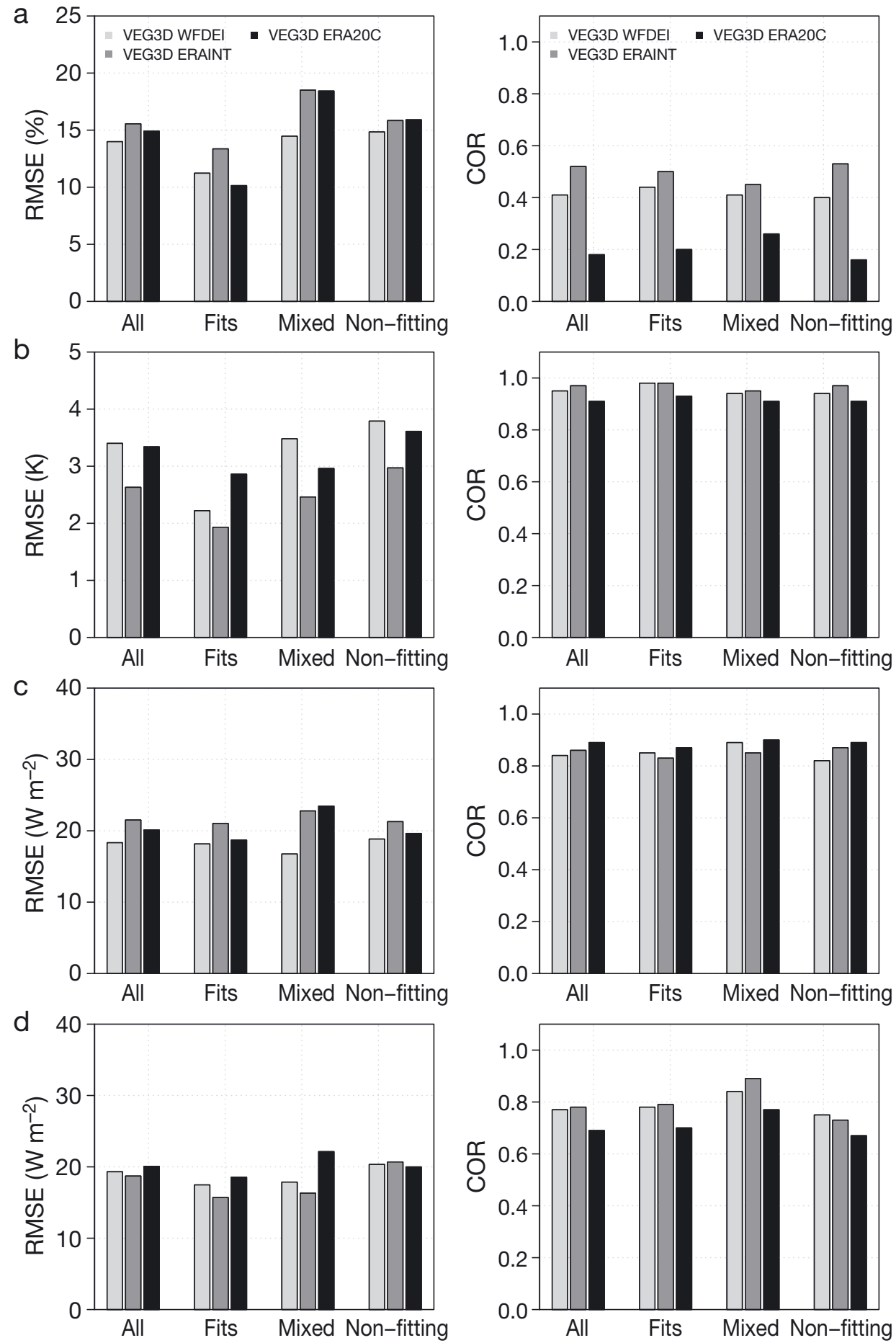

Fig. 2. Root mean square error (RMSE; left) and correlation (right) of the simulated monthly mean (a) soil water content in the uppermost soil layers, (b) soil temperatures in the uppermost soil layers, (c) latent and (d) sensible heat fluxes of the 3 VEG3D stand-alone simulations compared to the observational stations

For the yearly mean soil temperature (Fig. 2b), correlations are considerably higher, but within-group variation is small. VEG3D-ERAINT has again the highest correlation with the observations, VEG3DERA20C the lowest. Correlation varies significantly $(\mathrm{p}=0.06)$ with atmospheric forcing (Table 2). The within-group variation of the RMSE is quite pronounced, but a significant $(p=0.06)$ variation was only found for the external data; the Fits have clearly lower values than the other 3 categories. In contrast 
Table 2. $p$-values for Kruskal-Wallis test with a significance level of $\alpha=0.1$, for soil water content, soil temperature, latent heat flux and sensible heat flux, for the groups 'atmospheric forcing' and 'external data', regarding root mean square error (RMSE) and correlation, for the VEG3D standalone simulations. Only significant values are shown

\begin{tabular}{|lcccc|}
\hline & $\begin{array}{c}\text { Soil } \\
\text { water } \\
\text { content }\end{array}$ & $\begin{array}{c}\text { Soil } \\
\text { temperature }\end{array}$ & $\begin{array}{c}\text { Latent } \\
\text { heat } \\
\text { flux }\end{array}$ & $\begin{array}{c}\text { Sensible } \\
\text { heat } \\
\text { flux }\end{array}$ \\
\hline RMSE vs. forcing & - & - & 0.1 & - \\
RMSE vs. external data & 0.06 & 0.06 & - & - \\
Correlation vs. forcing & 0.03 & 0.06 & - & - \\
Correlation vs. external data & - & - & - & - \\
\hline
\end{tabular}

to the soil moisture results, VEG3D-ERAINT has the lowest bias for soil temperature, and VEG3D-WFDEI has the highest.

The simulated turbulent heat fluxes are in generally good agreement to the observed fluxes at the EFDC stations; variation of both RMSE and correlation with the 2 factors is small. Significant variation $(p=0.1)$ is only found for the RMSE on atmospheric forcing (Table 2). The best results for the latent heat fluxes is achieved by VEG3D-ERA20C (Fig. 2c). Its RMSE is moderate and the correlation reaches the highest values. For the sensible heat fluxes, VEG3DERAINT performs best (Fig. 2d). As already seen for the soil moisture and soil temperature, VEG3DERAINT shows the highest correlation with the observations. Additionally, the RMSE is lowest for this stand-alone run. Compared to the other quantities, for the turbulent heat fluxes, the differences between the 4 station categories are quite small and no significant variation was found. The Fits and the Non-fitting, for instance, have similar RMSEs for the latent heat fluxes. Also, the correlation of the simulated fluxes with the observed ones is not highest for the Fits, but for the Mixed. The differences between the 3 stand-alone simulations within a station category are larger than the differences between the different station categories themselves. The impact of the external data on the quality of the simulated turbulent heat fluxes is therefore smaller than for soil moisture and soil temperature.

\subsubsection{Comparison to spatial validation datasets}

In this section, the results of the 2-dimensional VEG3D stand-alone runs are compared to the spatial validation datasets for the Central European domain (Fig. 1). The comparison is done for the soil water content of the upper soil.
Fig. 3 shows the yearly mean water content in the upper soil over the period 1991-2010 for the stand-alone runs (Fig. $3 \mathrm{a}-\mathrm{c}$ ) and the validation datasets (Fig. 3d-f). All 3 VEG3D stand-alone simulations (Fig. 3a-c) show very similar moisture patterns, with very wet regions in the upwind area of the Vosges and at the North Sea coast. Drier regions are simulated in the western and eastern parts of Germany. Nevertheless, some slight differences can be observed. Smallscale structures of different land use classes like forests or coastal regions are more visible in VEG3D-ERAINT compared to especially VEG3D-WFDEI, since higher resolved external data are used.

In general, the simulated soil moisture patterns of all 3 VEG3D stand-alone runs match better to the observed ESA_CCI satellite data than the other validation datasets (Fig. 3d-f), although areas with strong deviations to the satellite data still exist (e.g. North Sea coast, Adriatic coast). The mapping of dry and moist regions within Central Europe is well resolved, in contrast to the ERA-Interim and the DWD_AMBAV data. In both products, the soil water contents all over Europe are considerably overestimated. These differences to the VEG3D stand-alone simulations cannot be explained by major differences in the atmospheric forcing datasets, since each of these simulations is driven by assimilated observations. But in contrast to VEG3D, the number of land use classes and soil types used in DWD_AMBAV and ERA-Interim is clearly reduced. Both DWD_AMBAV and TESSEL (LSM used in ERA-Interim) use only 1 soil type, and in DWD_AMBAV, additionally, only 1 land use class is applied. Thus, DWD_AMBAV and TESSEL are not able to resolve the small-scale structures in the soil water contents over Central Europe, caused by land use and soil heterogeneity, in the same magnitude as VEG3D. A proper mapping of the external data within LSM simulations is therefore essential for a realistic representation of spatial soil water contents in Europe.

\subsubsection{Assessment of VEG3D stand-alone runs}

In comparison to the other atmospheric forcing datasets, the stand-alone run with ERA-Interim forcing obtained the best agreement. Although minor differences occurred in the spatial validation of the single atmospheric forcing datasets, ERA-Interim 

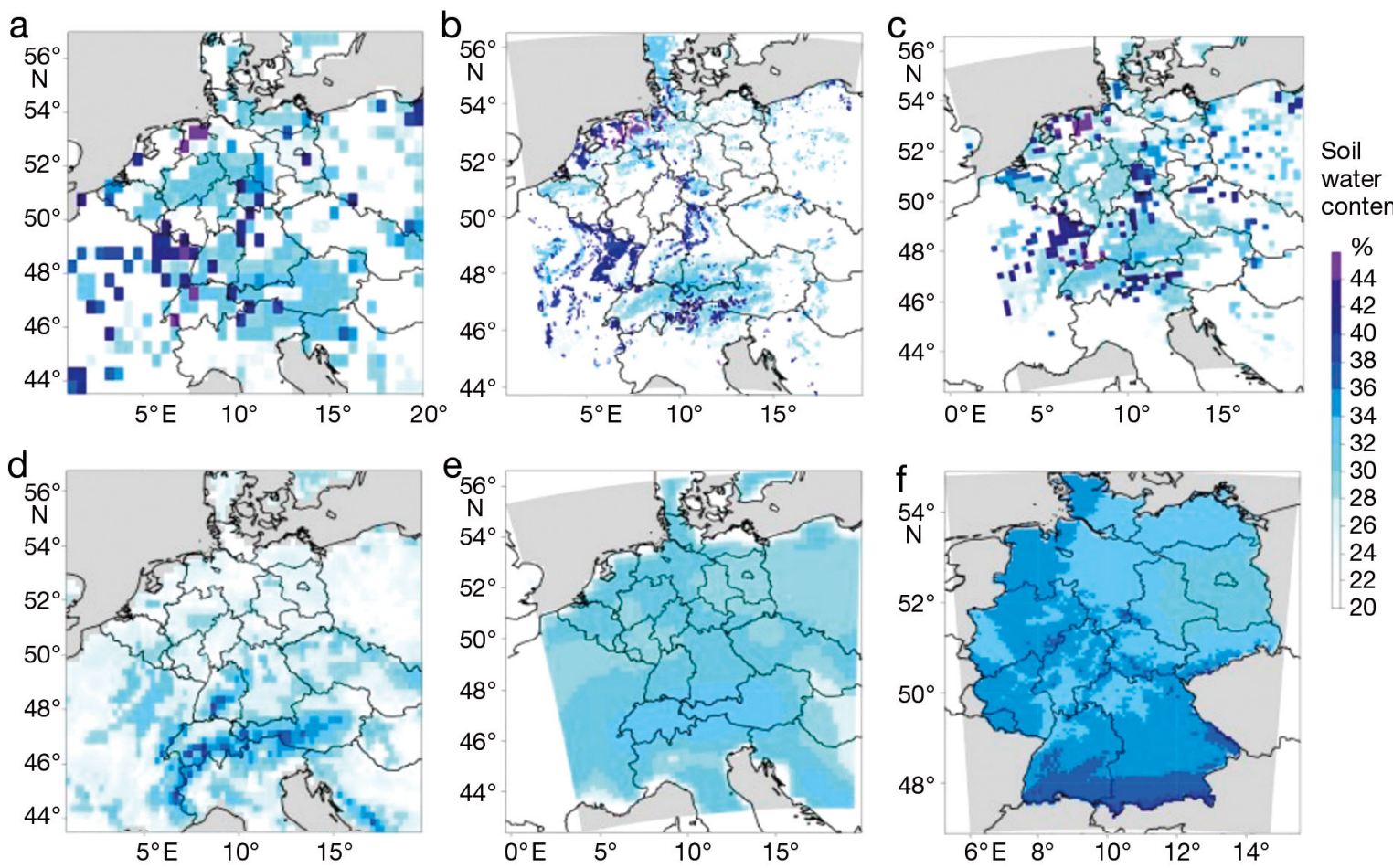

Fig. 3. Yearly mean water content in the upper soil over the period 1991-2001, for the stand-alone runs (a) VEG3D-WFDEI, (b) VEG3D-ERAINT, and (c) VEG3D-ERA20C, and the validation datasets (d) ESA_CCI, (e) ERA-Interim, and (f) DWD_AMBAV. Soil water content is calculated $\mathrm{as}^{3} / \mathrm{m}^{3}$, given as a percentage $(\%)$

performed clearly best in the validation with the EFDC measurement sites. It has a moderate RMSE and the highest correlation to the observed soil water contents, soil temperatures and sensible heat fluxes. Especially these high correlations to observations are very important for the soil initialization, since they reflect a good agreement to the modes of internal climate variations, which are essential for successful climate predictions (Marotzke et al. 2016). Only if such modes are correctly included in the soil initialization, can the predictive potential of soils be exploited. Soils initialized with uncorrelated climate modes therefore cannot achieve a predictive skill on a decadal timescale. Thus, an ERA-Interim-driven stand-alone simulation is chosen to provide initialization fields for the coupled decadal CCLM_VEG3D runs.

Furthermore, comparison of the 2-dimensional VEG3D stand-alone simulations with the EFDC measurement sites showed that the precision of the external data especially affects the bias of the simulated soil moisture and soil temperature at single points. But the correlation to the observations is mainly determined by the atmospheric forcing data, since it depends on the seasonal cycle induced by the atmospheric conditions. The impact of the external data on the accuracy of the simulated soil water con- tents can also be observed for the comparison with the spatial validation datasets. In contrast to validation datasets with a small range of external data (DWD_AMBAV and TESSEL), the VEG3D standalone simulations are able to properly reproduce the observed spatial soil moisture patterns in Central Europe (ESA_CCI). Thus, highly resolved external data in LSMs are an important factor for a realistic simulation of the land surface processes in Europe. But as shown in Section 4.1.1, the precision of the external data does not increase anymore between the $25 \mathrm{~km}$ and the $7 \mathrm{~km}$ resolution. Furthermore, the $7 \mathrm{~km}$ VEG3D stand-alone simulation does not show a clear added value compared to the $25 \mathrm{~km}$ simulation, regarding the spatial soil moisture patterns in Central Europe. Due to limited computing time, therefore, a coarser spatial resolution of $25 \mathrm{~km}\left(0.22^{\circ}\right)$ is chosen for the coupled decadal CCLM_VEG3D runs.

\subsection{Results of coupled CCLM-VEG3D simulations}

In this section, a possible added value of a balanced soil initialization for decadal climate predictions in Europe is analyzed. A decadal climate simulation, initialized with balanced soil conditions (CCLM_VEG3D_INIT), is compared to a refer- 
ence run, initialized by unbalanced soil conditions (CCLM_VEG3D_REF). The simulations are driven by ERA-Interim to ensure quasi-perfect lateral boundary conditions, for the assessment of the pure impact of a balanced soil initialization. These balanced soil conditions are derived from a VEG3D stand-alone simulation, driven by ERA-Interim. The reference run is initialized by the soil conditions of ERAInterim, which are not in balance with the VEG3D ones.

\subsubsection{Changes in initial soil water and temperature fields}

The differences in the initialization fields for soil temperature and soil water between the balanced soil conditions of CCLM_VEG3D_INIT and the unbalanced soil conditions of CCLM_VEG3D_REF are summarized in Table 3. The differences in the initialization fields are written as field means over the whole European model domain. For the evaluation, the soil is divided into 3 compartments: the upper soil layer $(0-1 \mathrm{~m})$ comprising the main part of the root zone, an intermediate section (1-2 m) and the deep soil layer $(2-10 \mathrm{~m})$. Table 3 shows that in each layer, the balanced soil of CCLM_VEG3D_ INIT is warmer and drier than the soil in CCLM_ VEG3D_REF. In particular, distinct differences appear in the deeper soil layers. In the upper layers, the differences in soil temperature and water content are less pronounced, since these layers are directly affected by the atmospheric forcing conditions (ERA-Interim in both cases), in contrast to the deeper layers. Thus, model-specific differences between VEG3D and TESSEL (LSM in the ERA-Interim reanalysis) seem to have a stronger and longer-lasting effect on the soil conditions in the deep soil than in the upper layers.

Table 3. Differences in the initialization fields for soil temperature and soil water between the coupled CCLMVEG3D simulations: CCLM_VEG3D_INIT and CCLM_ VEG3D_REF. Differences in the initialization fields are written as field means over the whole European model domain for 3 soil components: $0-1 \mathrm{~m}, 1-2 \mathrm{~m}$ and $2-10 \mathrm{~m}$ depth

\begin{tabular}{|lcc|}
\hline Depth $(\mathrm{m})$ & $\begin{array}{c}\text { Soil temperature } \\
(\mathrm{K})\end{array}$ & $\begin{array}{c}\text { Soil water content } \\
(\%)\end{array}$ \\
\hline $0-1$ & 2.9 & -7.33 \\
$1-2$ & 5.31 & -7.14 \\
$2-10$ & 5.08 & -8.05 \\
\hline
\end{tabular}

\subsubsection{Effects on decadal climate variability in Europe}

In order to distinguish between short-term and long-term effects of differences in the soil initialization on decadal climate simulations, 2 evaluation periods are analyzed: 2001-2005 and 2006-2010. Furthermore, the evaluation of the decadal simulations is divided into summer (June, July, August) and winter seasons (December, January, February), to take potential seasonal effects into account.

Fig. 4 shows the differences of the RSME of the seasonal precipitation sums between the balanced run (CCLM_VEG3D_INIT) and the reference run (CCLM_VEG3D_REF) for the period 2001-2005 (left) and the period 2006-2010 (right), for summer (Fig. 4a) and winter (Fig. 4b). The E_OBS observations (Haylock et al. 2008) are used as reference for the RMSE calculation. In winter, there are virtually no differences between the balanced run and the reference run for both periods. As could be expected, the initial soil fields have almost no impact on the seasonal precipitation sums in winter, since the winter rainfall is usually of synoptic origin. But in summer, differences amount up to about $\pm 50 \mathrm{~mm}$ over almost all of Europe in both evaluation periods. This means that soil initialization affects the simulated spatial rainfall distribution in summer over the whole prediction period. The soil conditions therefore have an influ-
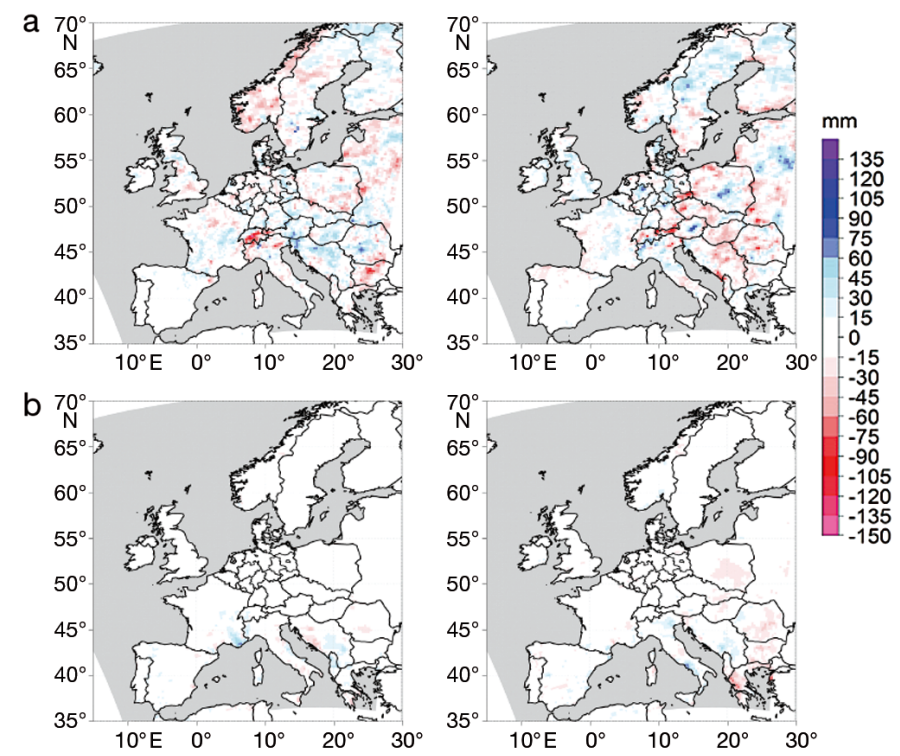

Fig. 4. Root mean square error (RMSE) differences in the seasonal precipitation sums between CCLM_VEG3D_INIT and CCLM_VEG3D_REF for the period 2001-2005 (left side) and 2006-2010 (right side), for (a) summer (JJA) and (b) winter (DJF) 
ence on the development of convective rainfall mainly in summer. The Iberian Peninsula, where the RMSE differences are very low, is an exception. This could be expected, since during summer very little rainfall occurs in any case, particularly in the southern part of this region. On the other hand, the spatial differences of the seasonal precipitation sums over the rest of Europe seem to be more or less randomly distributed. Therefore, no systematic improvement due to balanced soil initialization is found in the case of summer precipitation in Europe. This is also evident in the domain-averaged RMSE values for precipitation, listed in Table 4 for the whole European continent, Scandinavia and the Iberian Peninsula. Although big differences in the seasonal precipitation sums exist locally, due to their random distribution, no differences occur for large area means, proving that balanced soil initialization has no systematic added value for European summer precipitation.

In Fig. 5, the same RMSE differences are shown as in Fig. 4, but for the seasonal averages of the $2 \mathrm{~m}$ temperatures. For both evaluation periods and in both seasons, clear seasonal patterns between the balanced run and the reference run can be recognized. In the period 2001-2005, the winter RMSE values of the balanced run are in many parts of Europe larger than those of the reference run, especially in southern Scandinavia. By contrast, the balanced run has generally smaller RMSE values in summer than

Table 4. Domain-averaged root mean square errors (RMSEs) for (a) precipitation (mm) and (b) $2 \mathrm{~m}$ temperature (K) for the whole European continent, Scandinavia, and the Iberian Peninsula, for summer (JJA) and winter (DJF) season for the periods 2001-2005 and 2006-2010, for the coupled CCLMVEG3D simulations. E_OBS observations are used as reference for the RMSE calculation

\begin{tabular}{|c|c|c|c|c|c|c|}
\hline \multirow[t]{2}{*}{ (a) } & \multicolumn{2}{|c|}{ Europe } & \multicolumn{2}{|c|}{ Iberian Peninsula } & \multicolumn{2}{|c|}{ Scandinavia } \\
\hline & JJA & DJF & JJA & DJF & JJA & DJF \\
\hline \multicolumn{7}{|l|}{$2001-2005$} \\
\hline CCLM_VEG3D_REF & 53.72 & 34.96 & 28.02 & 42.66 & 60.88 & 49.46 \\
\hline CCLM_VEG3D_INIT & 53.29 & 35.45 & 31.33 & 43.98 & 59.38 & 48.53 \\
\hline \multicolumn{7}{|l|}{$2006-2010$} \\
\hline CCLM_VEG3D_REF & 61.35 & 58.91 & 34.76 & 56.50 & 64.38 & 45.42 \\
\hline CCLM_VEG3D_INIT & 60.50 & 57.08 & 31.73 & 57.29 & 69.15 & 45.07 \\
\hline \multirow[t]{2}{*}{ (b) } & \multicolumn{2}{|c|}{ Europe } & \multicolumn{2}{|c|}{ Iberian Peninsula } & \multicolumn{2}{|c|}{ Scandinavia } \\
\hline & JJA & DJF & JJA & DJF & JJA & DJF \\
\hline \multicolumn{7}{|l|}{ 2001-2005 } \\
\hline CCLM_VEG3D_REF & 1.01 & 1.49 & 1.11 & 1.32 & 1.17 & 1.40 \\
\hline CCLM_VEG3D_INIT & 0.99 & 1.58 & 0.95 & 1.43 & 1.13 & 1.52 \\
\hline \multicolumn{7}{|l|}{$2006-2010$} \\
\hline CCLM_VEG3D_REF & 1.08 & 1.59 & 1.15 & 1.68 & 1.18 & 1.52 \\
\hline CCLM_VEG3D_INIT & 1.09 & 1.59 & 1.22 & 1.54 & 1.18 & 1.53 \\
\hline
\end{tabular}
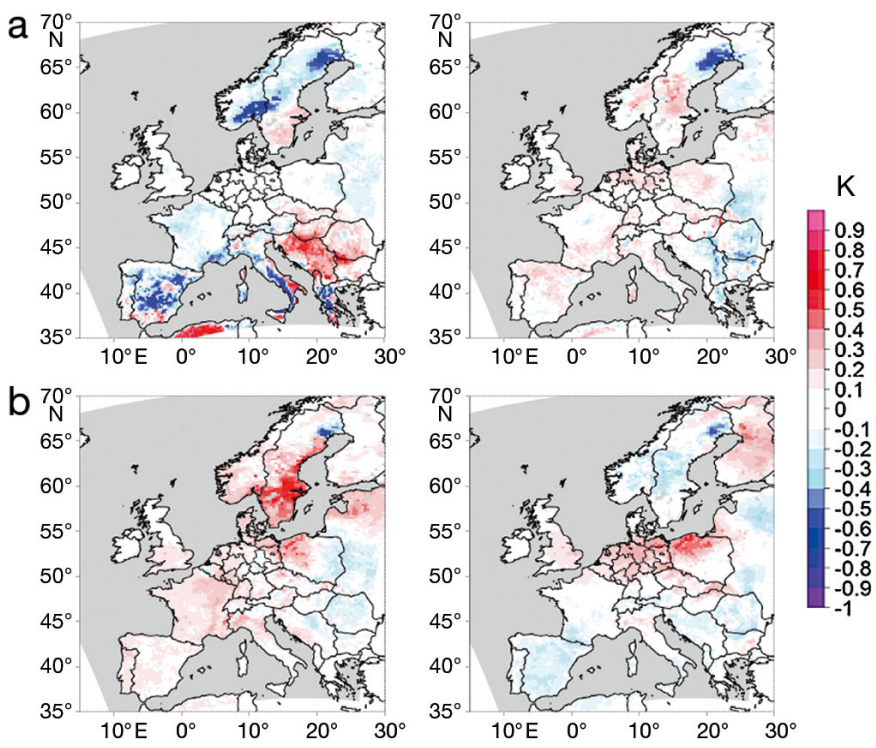

Fig. 5. Root mean square error (RMSE) differences in the seasonal $2 \mathrm{~m}$ temperatures between CCLM_VEG3D_INIT and CCLM_VEG3D_REF for the period 2001-2005 (left side) and 2006-2010 (right side), for (a) summer (JJA) and (b) winter (DJF)

the reference run all over Europe, with the exception of the Balkan region. Especially on the Iberian Peninsula, much of the Mediterranean region and Scandinavia, the balanced run performs better. These seasonal RMSE differences become smaller and sometimes even change sign during the second period 2006-2010. Therefore, for the first simulation years, an improvement due to balanced soil initialization can be observed in summer, whereas in winter, no improvement is found in the case of the $2 \mathrm{~m}$ temperatures.

Overall, the simulated $2 \mathrm{~m}$ temperatures seem to be quite sensitive to differences in the soil initialization in 3 regions: the Iberian Peninsula, Scandinavia and the Balkan region. In the Balkan region, both simulations show a strong warm bias in summer, which is more intense in the balanced run than in the reference run. Similar warm biases in this region are already observed in other CCLM simulations and also in other RCMs for the EURO-CORDEX domain (Kotlarski et al. 2014). This may point to a general problem of RCMs in this region or to a problem with the observations in the Balkan region. Therefore, the results of the Balkan region 
are not further discussed in detail; instead, the focus of the analysis is on the Iberian Peninsula and Scandinavia.

Soil water content is a quantity of particular importance for the soil and near-surface temperatures in these 2 regions. It affects via 2 main processes the heat balances of the soil, the surface and the boundary layer:

(1) A dry soil, like that seen in the initial field of the balanced run, has a lower heat capacity than a wet soil (reference run). As a result, the temperature of a dry soil reacts stronger and faster to changes in the thermal energy forcing, and the amplitude of the seasonal cycle of the soil temperature increases.

(2) In a dry soil, the amount of plant-available water for evapotranspiration is reduced. Thus, more thermal energy can be used to heat up the soil instead of evapotranspirating water from the soil. Consequently, more sensible heat is released into the atmosphere, resulting in increased near-surface temperatures. Due to the generally low input of thermal energy in winter, this process is mainly important in summer.

The results on the Iberian Peninsula (Fig. 6) and Scandinavia (Fig. 7) can be explained in terms of these 2 land-atmosphere processes.

On the Iberian Peninsula, the soil water content in the reference run does not reach equilibrium during the whole simulation period (Fig. 6e,f). In this study, we assume that equilibrium is reached when the temporal differences between the reference run and the balanced run are constantly inside $\mathrm{a} \pm 1$ standard deviation limit. In both the upper and the deeper soil layers, the reference run has a higher soil water content than the balanced run and does not fall below the standard deviation limit over the whole simulation period. Still, the soil water differences are getting smaller over the course of the simulation. Thus, due to process (1), the balanced run with its drier soil conditions exhibits an increased seasonal cycle of the upper soil temperatures (Fig. 6c) and the $2 \mathrm{~m}$ temperature (Fig. 6a). Especially during the first years of the simulation, the summer temperatures are considerably higher and in better agreement with the observed $2 \mathrm{~m}$ temperatures. Over the course of the simulated years, the seasonal temperatures of both runs converge. In winter, temperatures are lower than in the reference run, leading to a small cold bias. However, the differences in winter are not as pronounced as in summer. This effect is caused by process (2). In this context, the lower water reservoir in the balanced simulation substantially affects the water cycle of the Iberian Peninsula, since it is a soil- moisture-limited evapotranspiration regime (Seneviratne et al. 2010). Until 2007, latent heat fluxes in summer are considerably lower than in the reference run (Fig. 6b), resulting in higher $2 \mathrm{~m}$ temperatures. In the year 2007, differences in soil water content in summer still appear between both simulations. But in this case, this has no effect on the amount of the latent heat fluxes and in consequence on the $2 \mathrm{~m}$ temperatures. The reason for this is most likely that summer 2007 was recorded as relatively cold in this region. Thus, summer evapotranspiration was low and the latent heat fluxes in the balanced run were not limited by soil water availability. Consequently, no differences in the latent heat fluxes and the $2 \mathrm{~m}$ temperatures could be observed (Fig. 6a,b).

In Scandinavia, the balanced run also simulates lower soil water contents and a higher seasonal soil temperature cycle than the reference run (Fig. $7 \mathrm{C}-\mathrm{f}$ ). But in contrast to the Iberian Peninsula, this has just a minor impact on the evapotranspiration rate in summer (Fig. 7b). Latent heat fluxes in regions like Scandinavia are not limited by the availability of soil moisture, but by the incoming net shortwave radiation (Teuling et al. 2009). Process (2) has therefore almost no effect on near-surface temperatures in summer. Much more important for the seasonal temperature cycle in Scandinavia is process (1). The reduced heat capacity in the drier soil of the balanced run leads to a slightly increased seasonal cycle in the soil (Fig. $7 \mathrm{c}, \mathrm{d}$ ). This physical relation is particularly noticeable during the first 2 simulation years when the differences in the soil water content between both simulations are highest. Because of that, the balanced run has an added value in summer during the first part of the simulation (between 2001 and 2005, Fig. 5). But in the winter season, the effect is the opposite. Another difference to the Iberian Peninsula is that the soil water content in the upper soil reaches nearly balanced conditions after only 8 simulation years (Fig. 7e).

\section{DISCUSSION AND CONCLUSIONS}

The goal of the study was to investigate the potential added value of an initialization with balanced soil conditions for regional decadal climate predictions. To achieve the best possible balanced soil conditions, stand-alone simulations with the LSM VEG3D driven by different atmospheric forcing datasets were performed and evaluated. Based on the above, a decadal climate simulation driven by the quasi-perfect lateral boundary conditions of ERA-Interim was initialized 

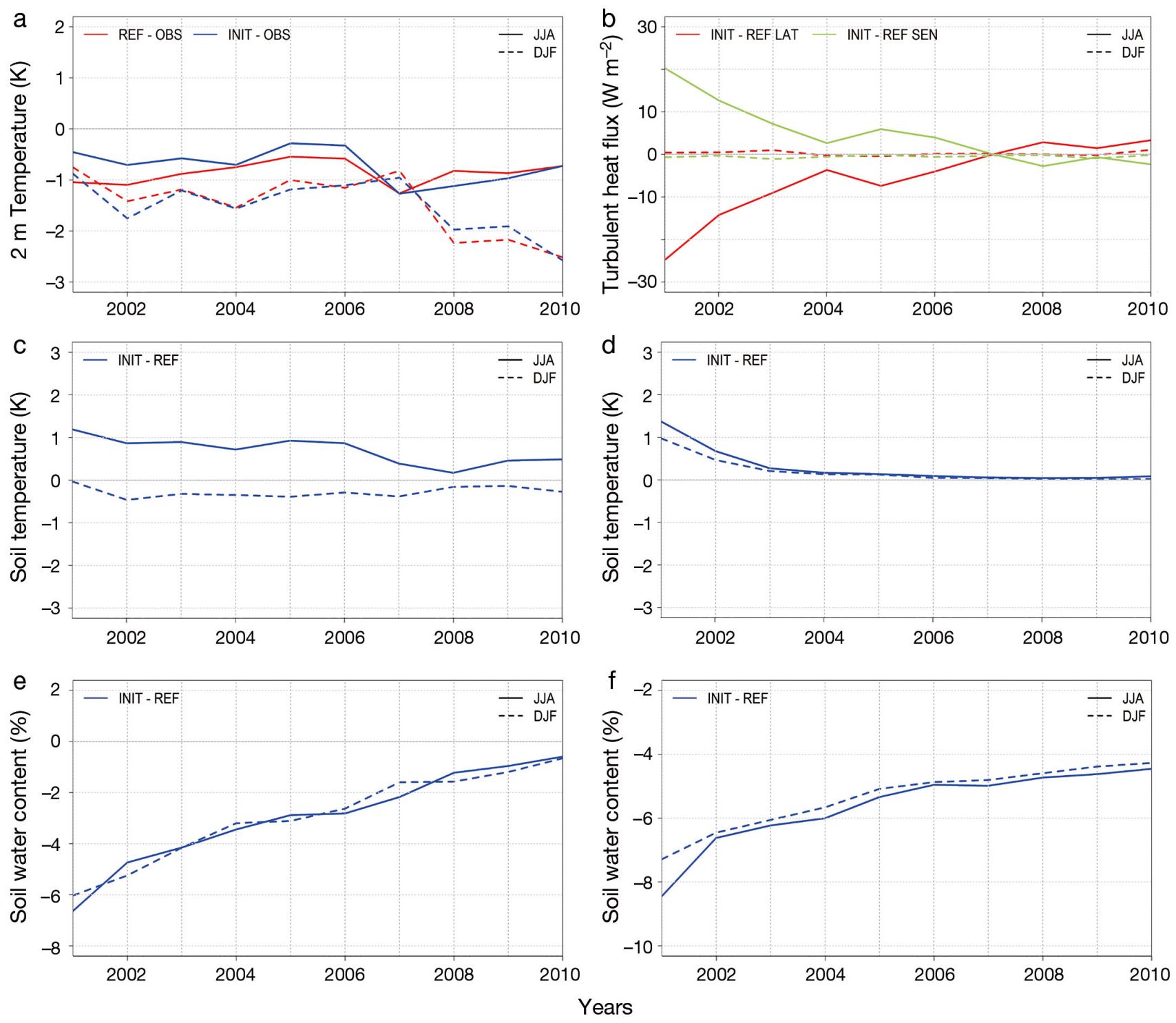

Fig. 6. Differences between CCLM_VEG3D_INIT and CCLM_VEG3D_REF for the seasonal field mean values for summer (JJA) and winter (DJF) on the Iberian Peninsula over the period 2001-2010, for (a) 2 m temperature, (b) turbulent heat fluxes, (c) upper soil temperature, (d) deeper soil temperature, (e) upper soil water content and (f) deeper soil water content

with these balanced soil conditions and compared to a decadal simulation, initialized by unbalanced soil conditions (ERA-Interim initialization). The main results of this study are as follows:

- The best approximation of the actual soil state is achieved by a VEG3D stand-alone simulation driven with ERA-Interim.

- The soil initialization has an impact on the spatial variability of summer precipitation in Europe, but no systematic added value of a balanced soil initialization can be observed.

- A balanced soil initialization systematically improves the simulation of summer temperatures in Europe, but not winter.
- The seasonal added value of a balanced soil initialization is more pronounced in warm and semiarid regions like the Iberian Peninsula than in coldhumid areas like Scandinavia.

In general, the results of the VEG3D stand-alone simulations are consistent with results from other studies evaluating the performance of other LSMs in comparison to measurement sites (Stockli et al. 2008, Zink et al. 2017). The simulation driven with ERAInterim gave the best results, showing a high correlation with observed soil temperatures and soil water contents. Furthermore, the simulation results revealed that the correlation to the observations mainly depends on the quality of the atmospheric 

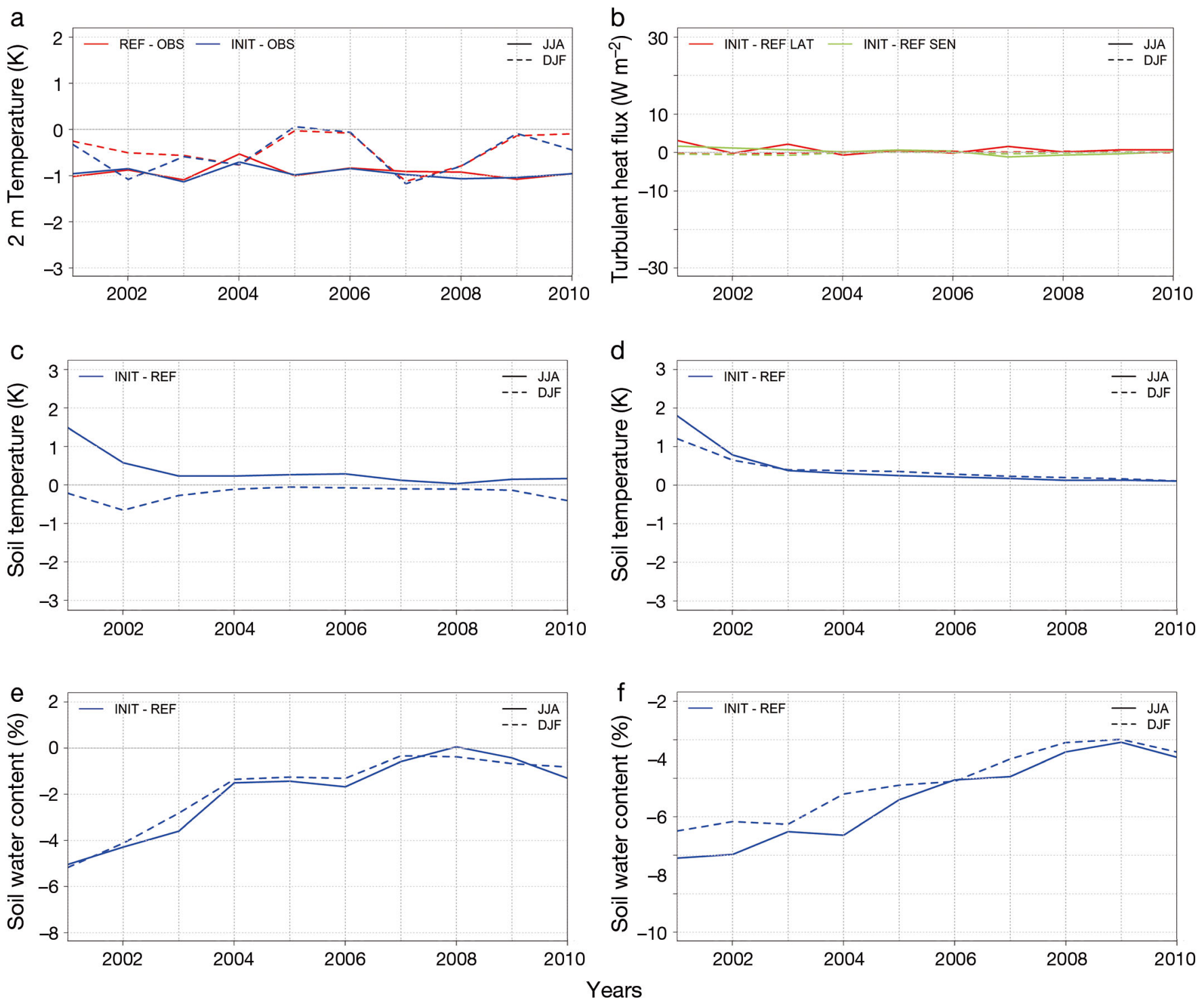

Fig. 7. Differences between CCLM_VEG3D_INIT and CCLM_VEG3D_REF for the seasonal field mean values for summer (JJA) and winter (DJF) in Scandinavia over the period 2001-2010, for (a) $2 \mathrm{~m}$ temperature, (b) turbulent heat fluxes, (c) upper soil temperature, (d) deeper soil temperature, (e) upper soil water content and (f) deeper soil water content

forcing data, inducing the soil temperature and water content seasonality. Thus, an ERA-Interim-driven VEG3D stand-alone simulation in a spatial resolution of $0.22^{\circ}$ was chosen to create balanced soil conditions for the initialization of the decadal run.

Comparison of the simulation with balanced soil initialization with a reference run with unbalanced soil initialization revealed that the soil initialization of decadal climate simulations considerably affects the spatial variability of summer precipitation in Europe over the whole simulation period. In winter, the impact on the rainfall variability is very small. Thus, the initial soil conditions have mainly an influence on the development of convective rainfall in summer and not on the synoptic rainfall in winter. In this context, no sensitive areas in the sense of a strong coupling between soil conditions and precipitation in summer can be identified, confirming the results of other studies (e.g. Koster et al. 2004). This is most likely because the local recycling of precipitation is generally rather small in Europe (Schär et al. 1999). Even for summer convection, large-scale atmospheric circulation conditions, and thus advection, are more important for the spatial rainfall distribution than local land surface characteristics, like soil type and land use class. But nevertheless, convection is a highly stochastic process, depending on local conditions (e.g. Pielke et al. 1997, Pal \& Eltahir 2001), 
which are not fully represented in regional climate simulations with a spatial resolution of $25 \mathrm{~km}$. Such simulations are consequently not able to exploit the full potential of an improved soil initialization. It can therefore be expected that especially highly resolved regional climate simulations $(<3 \mathrm{~km}$ spatial resolution) can benefit from balanced initial soil conditions. This conclusion is also in line with the findings of other studies (e.g. Prein et al. 2013, Rasmussen et al. 2014).

Regarding the evaluation of the simulated temperatures, the initialization with balanced soil conditions has positive effects on the simulation results, in line with Kothe et al. (2016). But in contrast to Kothe et al. (2016), we provide evidence of the different seasonal sensitivity to soil initialization. Especially in summer, the initialization with balanced soil conditions exhibits a clear added value for the simulated temperatures in warm and semi-arid regions like the Iberian Peninsula. In such areas, the evapotranspiration is limited by the availability of soil water (Seneviratne et al. 2010). Thus, an initialization with a very high soil water content, like in the simulation with unbalanced soil conditions, is not able to reproduce the characteristic drought stress in summer (VicenteSerrano et al. 2014) and the associated changes in the Bowen ratio (Jerez et al. 2010), resulting in underestimated near-surface temperatures. This is especially true for the first years of the simulation until the soil water content of both simulations is getting very close in the upper soil layers, where plant-available water is stored. During the winter season, evapotranspiration is reduced and the different heat capacities of dry and wet soils are getting more important for near-surface temperatures. The initialization with a very low soil water content, like in the simulation with balanced soil conditions, leads to underestimated $2 \mathrm{~m}$ temperatures in winter.

Since the evapotranspiration regime in cold-humid regions like Scandinavia is not limited by the availability of soil water (Teuling et al. 2009), the seasonal cycle of near-surface temperatures is mainly influenced by soil heat capacity. Dry soils, like in the simulation with balanced soil conditions, exhibit an increased seasonal cycle, leading to a better agreement with observations in summer during the first simulation years, but also to an increased bias in winter. But in comparison to warm and semi-arid regions, the impact of soil initialization on near-surface temperatures is rather small. Thus, the extent of a possible added value of balanced soil conditions for the initialization of decadal climate predictions depends on the type of the evapotranspiration regime.
Another striking difference between warm and semi-arid and cold-humid regions is the time period until the soil reaches balanced conditions. Unlike Scandinavia, the upper soil water content in the simulation with unbalanced soil initialization does not reach equilibrium in the Iberian Peninsula within the whole prediction period. This can be explained with the different hydraulic conductivities and hydraulic diffusivities in dry and wet soils (van Genuchten 1980). The water flow through a dry soil is slower than through a wet soil, as described by the Richards equation. Thus, perturbations in the soil initialization in warm and semi-arid regions are slowly balanced out, while perturbations in cold-humid areas vanish much faster. This finding confirms the results of other studies about the initialization of soils in different climates (e.g. Khodayar et al. 2015). In consequence, the soil conditions (especially soil water content) at initialization affect the atmospheric conditions on the Iberian Peninsula over a longer timescale than in Scandinavia. Inaccuracies in the soil initialization of decadal predictions therefore should have especially an impact in warm and semi-arid regions on the quality of the simulated summer temperatures, as already suggested by the results of climate projections for the Iberian Peninsula (Jerez et al. 2012).

These findings may become important on the European scale, given that recent climate projections indicate that the climate in Europe will become more extreme, especially in regions which are supposed to become warmer and drier in summer, like Central and Eastern Europe (Schär et al. 2004, Seneviratne et al. 2012). Consequently, the moderate evapotranspiration regimes in these areas might temporally evolve to soil-moisture-limited regimes (Seneviratne et al. 2006). Thus, inaccuracies in the soil initialization in these regions may affect the quality of decadal predictions in the future much stronger than today. This is especially true for the prediction of extreme events, like heatwaves, when the soils may dry out (Miralles et al. 2014). Since the number of such heatwaves is likely to increase (Meehl \& Tebaldi 2004), an accurate soil initialization for decadal predictions may be of growing importance.

Acknowledgements. We acknowledge funding by the Federal Ministry of Education and Research in Germany (BMBF) under the MiKlip II research program (FKZ: 01LP1518A). We thank ECMWF for their ERA-Interim Reanalysis (http:// apps.ecmwf.int/datasets/). This work used data acquired and shared by the European Fluxes Data Cluster, including these networks: EuroFlux, GHG-Europe, CarboExtreme, CarboEuropeIP, CarboEuroFlux, CarboMont, CarboItaly, IMECC, GreenGrass and ICOS. J.G.P. thanks the AXA Research Fund for support. 


\section{LITERATURE CITED}

Baldauf M, Seifert A, Förstner J, Majewski D, Raschendorfer M (2011) Operational convective-scale numerical weather prediction with the COSMO model: description and sensitivities. Mon Weather Rev 139:3887-3905

Balsamo G, Viterbo P, Beljaars A, van den Hurk B, Hirschi M, Betts AK, Scipal K (2009) A revised hydrology for the ECMWF model: verification from field site to terrestrial water storage and impact in the integrated forecast system. J Hydrometeorol 10:623-643

*Bartholomé E, Belward AS (2005) GLC2000: a new approach to global land cover mapping from Earth observation data. Int J Remote Sens 26:1959-1977

Boone A, de Rosnay P, Balsamo G, Beljaars A and others (2009) The AMMA Land Surface Model Intercomparison Project (ALMIP). Bull Am Meteorol Soc 90:1865-1880

Braun FJ, Schädler G (2005) Comparison of soil hydraulic parameterizations for mesoscale meteorological models. J Appl Meteorol 44:1116-1132

Breil M, Schädler G (2017) Quantification of the uncertainties in soil and vegetation parameterizations for regional climate simulations in Europe. J Hydrometeorol 18: 1535-1548

Breil M, Panitz HJ, Schädler G (2017) Impact of soilvegetation-atmosphere interactions on the spatial rainfall distribution in the Central Sahel. Meteorol Z (Berl) 26:379-389

Breil M, Schädler G, Laube N (2018) An improved soil moisture parametrization for regional climate simulations in Europe. J Geophys Res Atmos 123:7331-7339

*Dee DP, Uppala SM, Simmons AJ, Berrisford P and others (2011) The ERA-Interim reanalysis: configuration and performance of the data assimilation system. Q J R Meteorol Soc 137:553-597

* Dirmeyer PA, Kumar S, Fennessy MJ, Altshuler EJ and others (2013) Model estimates of land-driven predictability in a changing climate from CCSM4. J Clim 26:8495-8512

Doms G, Baldauf M (2015) A description of the nonhydrostatic regional COSMO-model. I. Dynamics and numerics. Tech Rep. Consortium for Small-Scale Modelling

* Dorigo WA, Gruber A, De Jeu RAM, Wagner W and others (2015) Evaluation of the ESA CCI soil moisture product using ground-based observations. Remote Sens Environ 162:380-395

Etchevers P, Martin E, Brown R, Fierz C and others (2004) Intercomparison of the surface energy budget simulated by several snow models (SNOWMIP project). Ann Glaciol 38:150-158

Fischer GF, Nachtergaele F, Prieler S, van Velthuizen HL, Verelst L, Wiberg D (2008) Global agro-ecological zones assessment for agriculture (GAEZ 2008). Tech Rep. International Institute for Applied Systems Analysis (IIASA), Laxenburg, and FAO, Rome

*Haylock M, Hofstra N, Klein Tank A, Klok E, Jones P, New M (2008) A European daily high-resolution gridded data set of surface temperature and precipitation for 19502006. J Geophys Res 113:D20119

Jacob D, Petersen J, Eggert B, Alias A and others (2014) EURO-CORDEX: new high-resolution climate change projections for European impact research. Reg Environ Change 14:563-578

Jerez S, Montavez JP, Gomez-Navarro JJ, Jimenez-Guerrero P, Jimenez J, Gonzalez-Rouco JF (2010) Temperature sensitivity to the land-surface model in MM5 climate simulations over the Iberian Peninsula. Meteorol Z (Berl) 19:363-374

Jerez S, Montavez JP, Gomez-Navarro JJ, Jimenez PA, Jimenez-Guerrero P, Lorente R, Gonzalez-Rouco JF (2012) The role of the land surface model for climate change projections over the Iberian Peninsula. J Geophys Res Atmos 117:D01109

Johansen O (1977) Thermal conductivity of soils. PhD thesis, University of Trondheim (in Norwegian)

K Khodayar S, Kalthoff N, Schädler G (2013) The impact of soil moisture variability on seasonal convective precipitation simulations. I. Validation, feedbacks, and realistic initialisation. Meteorol Z (Berl) 22:489-505

* Khodayar S, Sehlinger A, Feldmann H, Kottmeier C (2015) Sensitivity of soil moisture initialization for decadal predictions under different regional climatic conditions in Europe. Int J Climatol 35:1899-1915

Koster RD, Suarez MJ (2001) Soil moisture memory in climate models. J Hydrometeorol 2:558-570

Koster RD, Dirmeyer PA, Guo Z, Bonan G and others (2004) Regions of strong coupling between soil moisture and precipitation. Science 305:1138-1140

Kothe S, Tödter J, Ahrens B (2016) Strategies for soil initialization of regional decadal climate predictions. Meteorol Z (Berl) 25:775-794

Kotlarski S, Keuler K, Christensen OB, Colette A and others (2014) Regional climate modeling on European scales: a joint standard evaluation of the EURO-CORDEX RCM ensemble. Geosci Model Dev 7:1297-1333

* Larson J, Jacob R, Ong E (2005) The model coupling toolkit: a new Fortran90 toolkit for building multiphysics parallel coupled models. Int J High Perform Comput Appl 19: 277-292

Löpmeier FJ (1983) Agrarmeteorologisches Modell zur Berechnung der aktuellen Verdunstung (AMBAV). Deutscher Wetterdienst, Zentrale Agrarmeteorologische Forschungsstelle, Braunschweig

Marotzke J, Müller WA, Vamborg FSE, Becker P and others (2016) MiKlip: a national research project on decadal climate prediction. Bull Am Meteorol Soc 97:2379-2394

*Meehl GA, Tebaldi C (2004) More intense, more frequent, and longer lasting heat waves in the 21st century. Science 305:994-997

* Mieruch S, Feldmann H, Schädler G, Lenz CJ, Kothe S, Kottmeier C (2014) The regional MiKlip decadal forecast ensemble for Europe: the added value of downscaling. Geosci Model Dev 7:2983-2999

* Miralles DG, Teuling AJ, van Heerwaarden CC, VilàGuerau de Arellano J (2014) Mega-heatwave temperatures due to combined soil desiccation and atmospheric heat accumulation. Nat Geosci 7:345-349

Niu GY, Yang ZL, Mitchell KE, Chen F and others (2011) The community Noah land surface model with multiparameterization options (Noah-MP). I. Model description and evaluation with local-scale measurements. J Geophys Res Atmos 116:D12109

Oleson K, Lawrence DM, Bonan GB, Drewniak B and others (2013) Technical description of version 4.5 of the Community Land Model (CLM). Tech Note NCAR/TN-503+ STR. National Center for Atmospheric Research (NCAR), Boulder, CO

Pal JS, Eltahir EAB (2001) Pathways relating soil moisture conditions to future summer rainfall within a model of the land-atmosphere system. J Clim 14:1227-1242

Pielke RA, Lee TJ, Copeland JH, Eastman JL, Ziegler CL, 
Finley CA (1997) Use of USGS provided data to improve weather and climate simulations. Ecol Appl 7:3-21

Poli P, Hersbach H, Tan DGH, Dee DP and others (2013) The data assimilation system and initial performance evaluation of the ECMWF pilot reanalysis of the 20th-century assimilating surface observations only (ERA-20C). ERA Rep Ser 14. European Centre for Medium-Range Weather Forecasts (ECMWF), Shinfield Park

Prein AF, Gobiet A, Suklitsch M, Truhetz H, Awan NK, Keuler K, Georgievski G (2013) Added value of convection permitting seasonal simulations. Clim Dyn 41: 2655-2677

Rasmussen R, Ikeda K, Liu C, Gochis D and others (2014) Climate change impacts on the water balance of the Colorado headwaters: high-resolution regional climate model simulations. J Hydrometeorol 15:1091-1116

Rockel B, Will A, Hense A (2008) The regional climate model COSMO-CLM (CCLM). Meteorol Z (Berl) 17:347-348

Roeckner G, Bäuml G, Bonaventura L, Brokopf R and others (2003) The atmospheric general circulation model ECHAM 5. I. Model description. Tech Rep 349. MaxPlanck-Institut für Meteorologie, Hamburg

Schär C, Lüthi D, Beyerle U, Heise E (1999) The soilprecipitation feedback: a process study with a regional climate model. J Clim 12:722-741

Schär C, Vidale PL, Lüthi D, Frei C, Häberli C, Liniger MA, Appenzeller $C$ (2004) The role of increasing temperature variability in European summer heatwaves. Nature 427: 332-336

Schenk HJ, Jackson RB (2003) Global distribution of root profiles in terrestrial ecosystems. Oak Ridge National Laboratory (ORNL), Distributed Active Archive Center (DAAC), Oak Ridge, TN

Seneviratne SI, Lüthi D, Litschi M, Schär C (2006) Landatmosphere coupling and climate change in Europe. Nature 443:205-209

Seneviratne SI, Corti T, Davin EL, Hirschi M and others (2010) Investigating soil moisture-climate interactions in a changing climate: a review. Earth Sci Rev 99:125-161

Seneviratne SI, Nicholls N, Easterling D, Goodess CM and others (2012) Changes in climate extremes and their impacts on the natural physical environment. In: Field CB, Barros V, Stocker TF, Qin D and others (eds) Managing the risks of extreme events and disasters to advance climate change adaptation. A special report of Working Groups I and II of the Intergovernmental Panel on Climate Change (IPCC). Cambridge University Press, Cambridge, p 109-230

Editorial responsibility: Ricardo Trigo, Lisbon, Portugal
Shukla J, Mintz Y (1982) Influence of land-surface evapotranspiration on the Earth's climate. Science 215: 1498-1501

* Stöckli R, Lawrence DM, Niu GY, Oleson KW and others (2008) Use of FLUXNET in the Community Land Model development. J Geophys Res Biogeosci 113:G01025

* Teuling AJ, Hirschi M, Ohmura A, Wild M and others (2009) A regional perspective on trends in continental evaporation. Geophys Res Lett 36:L02404

Valcke S, Craig T, Coquart L (2015) OASIS3-MCT user guide OASIS3-MCT 3.0. CERFACS/CNRS SUC URA No1875. CERFACS, Toulouse

van den Hurk B, Viterbo P, Beljaars A, Betts A (2000) Offline validation of the ERA40 surface scheme. Tech Memo 295. European Centre for Medium-Range Weather Forecasts (ECMWF), Shinfield Park

* van den Hurk B, Best M, Dirmeyer P, Pitman A, Polcher J, Santanello J (2011) Acceleration of land surface model development over a decade of GLASS. Bull Am Meteorol Soc 92:1593-1600

* van den Hurk B, Kim H, Krinner G, Seneviratne SI and others (2016) LS3MIP (v1.0) contribution to CMIP6: the Land Surface, Snow and Soil moisture Model Intercomparison Project-aims, setup and expected outcome. Geosci Model Dev 9:2809-2832

van Genuchten M (1980) A closed-form equation for predicting the hydraulic conductivity of unsaturated soils. Soil Sci Soc Am J 44:892-898

*Vicente-Serrano SM, Lopez-Moreno JI, Beguería S, Lorenzo-Lacruz J and others (2014) Evidence of increasing drought severity caused by temperature rise in southern Europe. Environ Res Lett 9:044001

V Viterbo P, Beljaars A (1995) An improved land surface parameterization scheme in the ECMWF model and its validation. J Clim 8:2716-2748

Weedon GP, Gomes S, Viterbo P, Österle H and others (2010) The WATCH forcing data 1958-2001: a meteorological forcing dataset for land surface- and hydrological models. WATCH Tech Rep 22. www.eu-watch.org

*Will A, Akhtar N, Brauch J, Breil M and others (2017) The COSMO-CLM 4.8 regional climate model coupled to regional ocean, land surface and global Earth system models using OASIS3-MCT: description and performance. Geosci Model Dev 10:1549-1586

K Zink M, Kumar R, Cuntz M, Samaniego L (2017) A high-resolution dataset of water fluxes and states for Germany accounting for parametric uncertainty. Hydrol Earth Syst Sci 21:1769-1790

Submitted: September 5, 2018; Accepted: November 29, 2018 Proofs received from author(s): February 7, 2019 